\title{
SOME CAUSES OF CHICKEN'S GROWTH RETARDATION IN SHARKIA, EGYPT
}

\author{
L.K. ABD EL-SAMIE \\ Colleague at Veterinary Hospital, Faculty of Vet. Medicine, Zagazig University. \\ Email: lamahsamie@gmail.com
}

\section{ABSTRACT}

Received at: $26 / 10 / 2014$

Over six month period from July to December 2013, investigation of poor performance problem was carried out among meat type chicken populations that routinely immunized against Newcastle, Infectious bursitis, Infectious bronchitis

Accepted: 9/12/2014 and Avian Influenza at Minia El-kameh, Sharkia governorate, Egypt. Seventy stunted birds of different breeds aged between 20 and 40 days old were selected from eight private farms. Post mortem examination incriminated probable infection of Reo virus and E. coli. Total of 350 organs (provintireculus, pancreas, small intestine, thymus and heart) sampled for REO and 420 (liver, spleen, lung, joint, bile, heart blood) for E. coli isolation. Results showed that $35(10 \%)$ were positive REO virus identified by agar gel precipitation test and 34 (8.1\%) E coli serotyped $O_{55}, O_{78}, O_{119}$ and $O_{125}$. One hundred and forty day old chicks were deployed to conduct two experimental infections of the isolated virus and bacteria via different routes to evaluate its effect on chicken's performance and histological changes. In each experiment chickens were divided into 3 groups, 1 and 2 were infected with $E$. coli $O_{78}$ or REO while third group remained uninfected, served as control. Intramuscular infected groups recorded the highest mortalities and lower body weight comparing with oral and ocular route. Reisolation and histopathological changes confirmed pathogenicity of E. coli $O$ and REO virus respectively. It is recommended that further studies to be done on REO diversity and molecular characterization in Egypt whilst adoption of vaccination programs against Reo virus and $E$. coli infection especially for breeder hens considered an utmost need to avoid serious economic losses.

Key words: REO virus - E. coli O78 - Performance - Histopathology

\section{INTRODUCTION}

Escherichia coli is a commensally intestinal bacteria that commonly used to monitor resistance to therapeutically valuable antimicrobials in poultry (Jakobsen et al., 2010). Simultaneously, E. coli is as a major pathogen of widespread importance in commercially produced poultry contributing to significant economic losses (Hammerum and Heuer, 2009). A wide range of $E$. coli serogroups including $\mathrm{O}_{2}$ and $\mathrm{O}_{78}$ which are among most frequent have been isolated from poultry lesions due to colibacillosis (Dho-Moulin and Fairbrother 1999, Ewers et al., 2003 and Jamalludeen et al., 2009). Colibacillosis is one of the most important diseases of the poultry industry around the world causing either directly due to increased mortalities or indirectly by reduction of weight gain, high feed conversion rate and carcass condemnation (Saif 2008). It is seen clinically as acute colisepticemia, subacute fibrinopurulent serositis and as chronic granulomtous disease in viscera. In nearly all cases the disease is believed to arise by extension of inhaled litter dust contaminated with feaces to the lower respiratory tract and then to the blood stream. Thus Colibacillosis of domestic birds appears to be a respiratory tract disease that is maintained by carrier status of $E$. coli within the intestinal tract (Barnes 1994 and Ogunbanwo et al., 2004).

REO virus infections in poultry are prevalent worldwide. It has been isolated from chickens showing a wide variety of clinical signs including arthritis/tenosynovitis, malabsorption syndrome, pericarditis, myocarditis and immunosuppression (Mc Nulty 1993). Enteric REO virus strain (ERS) was isolated and identified from broilers in Poland showing high mortality. Usually this strain isolated from birds with malabsorption syndrome but on studying its pathogenicity and dissemination in specific pathogen free (SPF) chickens, it was able to induce a high mortality, tenosynovitis and malabsorbtion syndrome. Also commercial broilers with maternally derived antibodies against REO virus showed a growth retardation of 35 and $25 \%$ in broilers inoculated at day old and 7 days old, respectively, (Van Loon et al., 2001). Upon screening for REO in the field, it was observed that ERS are 
present in Netherlands, Belgium, Ireland, United Kingdom, Spain, Germany, Italy, USA, Argentina, United Arabic Emirates, South Africa, Philippines and Indonesia (Van de Zande and Lin 2005).

The study targeted virus and bacteria that may be responsible for stunting of the meat type broilers to be isolated and identified for minimization of economic losses risk as a result of deaths and poor performance.

\section{MATERIALS and METHODS}

Samples and specimens: Among 6 months period (July - December 2013) five to seven birds of different breeds and ages that showing uneven growth were collected from 8 private broiler farms at Minia El-Kameh, Sharkia governorate for laboratory examination. Clinical and postmortem findings were recorded after humanly scarification for each bird. Organs such as proventirculus, pancreas, small intestine, thymus, heart, lung, liver, spleen and joint in addition to heart blood and bile were harvested for viral and bacterial isolation.

Isolation, Identification and serotyping of bacteria: According to the standard bacteriological methods, blood, bile and organs (liver- spleen- lungjoint) were cultured on nutrient broth (BioMerieux), MacConkey's and Levins Eosin Methylene Blue agar (Oxoid). Isolates were identified by using E. coli diagnostic $\mathrm{O}$ antisera (Animal Health Research Institute, Dokki - Egypt) and slide agglutination test (Ewing 1984).

Isolation and Identification of virus: Small section of provintireculus, pancreas, small intestine, thymus and heart was treated with antibiotic solution (Penicillin $10000 \mathrm{IU} / \mathrm{ml}$, Streptomycin $10 \mathrm{mg} / \mathrm{ml}$, and Gentamycin $0.25 \mathrm{mg} / \mathrm{ml}$ ) and homogenized. $0.1 \mathrm{ml}$ of the homogenate was inoculated in Embryonated chicken eggs (ECE) via yolk sac resulting in embryonic death 3-5 days post inoculation then identified by agar gel precipitation test using standard REO antigen and antisera obtained from Serum and Animal Health Research institute Dokki - Egypt.

Experimental birds: One hundred and forty apparently healthy day old chicks, Hubbard breed obtained from commercial hatchery (Cairo Poultry Company) rose hygienically in isolated floor pens, fed on un-medicated growing ration feed and water was provided ad libtum.

Challenge: Two experimental infections were conducted in chicken groups. First one was carried out by inoculation of isolated $E$. coli $O_{78}, K_{80}$ suspension via different routes with $1 \times 10^{8} \mathrm{cfu} / \mathrm{ml}$ while second experiment was done by using isolated REO virus that titrated in ECE and the titer was expressed as $50 \%$ embryo infected dose $0.2 \mathrm{mlx} 10^{4.8}$.
Histopathology: According to the standard procedures, tissues of dead birds from REO challenged groups were fixed in $10 \%$ formalin, embedded in paraffin wax, processed to hematoxylin and eosin (HE) stained sections and microscopically examined.

Experimental design: 140 day old chicks were divided into 3 main groups. Chickens of the first group (60) were subdivided equally into A1, A2 and A3 infected with $1 \mathrm{mlx} 10^{8} \mathrm{cfu}$ of $E$. coli $\mathrm{O}_{78}$ at 14 days old via oral, ocular and imtramuscular (I/M), respectively. Chickens of the second group (60) similarly subdivided into B1, B2 and B3 but infected with $0.2 \mathrm{ml} \times 10^{4.8}$ of REO virus at day old. Chickens of third group were (20) remain uninfected control. Mortalities, Body weight (BW) and body gain (BG) were recorded and calculated for three weeks post infection. Blood and organs were collected for reisolation and histopathology (Table 1).

Statistical analysis: Data were collected, organized and analyzed using one-way analysis of variance (ANOVA) through the general linear models (GLM) procedure of the Statistical Package for Social Sciences version 22.0 (SPSS for Windows 22.0, Inc., Chicago, IL, USA). Duncan multiple range test were used to separate means at $\mathrm{p}<0.05$.

\section{RESULTS}

Seventy chickens aged between 20 and 40 days were randomly selected from ten farms in Minea Elkameh at Sharkia governorate that had a problem of uneven growth and mortality. Examined bird showed feather deformity, depression, droopy wings, diarrhea, pasty vent and mild respiratory manifestation. Post mortem findings showed anemic carcass, proventriculitis, pericarditis, air saculitis, peritonitis, perihepatitis, pancreatic atrophy, enteritis and the intestine filled with gases and contained undigested food. Bacteriological isolation showed that out of 420 specimens (heart blood, bile, liver, spleen, lung and joint) 34 was $E$. coli positive serotyped pathogenic $O_{55}(9), O_{78}(13), O_{119}(4)$ and $O_{125}(8)$. Viral isolation on embryonated chicken eggs (ECE) of 350 tissue samples (proventriculus, pancreas, small intestine, heart and thymus) showed that 35 were REO virus positive identified by agar gel precipitation test (Table 2).

Experimental infection with isolated E. coli $O_{78}(1$ $\left.\mathrm{ml} \times 10^{8} \mathrm{cfu}\right)$ via different route at 14 days old showed that $\mathrm{I} / \mathrm{M}$ yield $15 \%$ mortality in addition to significant decrease of body weight $652.3 \pm 1.74^{\mathrm{c}}, 1090.3 \pm 1.55^{\mathrm{c}}$ and $1175.3 \pm 4.15^{\mathrm{d}}$ at $1^{\text {st }}, 2^{\text {nd }}$ and $3^{\text {rd }}$ week post infection, respectively, and cumulative body gain $836.5 \pm 3.87^{\mathrm{e}}$ in comparison with not only control group but also oral and ocular infected groups. Postmortem examination revealed pericarditis, 
perihepatitis, enteritis and peritonitis. E. coli $O_{78}$ reisolation was $29.5 \%, 35 \%, 27 \%$ and $25.1 \%$ from air sac, heart, liver and spleen respectively, from infected groups.

Both oral and ocular infection with isolated REO virus with $0.2 \mathrm{ml} \times 10^{4.8}$ at day old caused $5 \%$ mortality while I/M infection induced $35 \%$ mortality. Macroscopic findings showed hydro pericardium, enlarged liver with necrotic foci, discolored enlarged spleen and enlarged proventriculus. Statistical analysis elaborated that there was a significant decrease of body's weight and gain of infected groups with REO virus comparing with control group while there was no significant difference between oral, ocular and $\mathrm{I} / \mathrm{M}$ at $1^{\text {st }}, 5^{\text {th }}$ and $6^{\text {th }}$ weeks post infection as well as cumulative body gain. Moreover $2^{\text {nd }}, 3^{\text {rd }}, 4^{\text {th }}$ week post infection with REO virus showed significant difference between body weight of $\mathrm{I} / \mathrm{M}$ group $606.2 \pm 1.04^{\mathrm{e}}, 299.6 \pm 1.08^{\mathrm{e}}$ and $230.7 \pm 0.71^{\mathrm{c}}$ respectively, and other infected groups (Table 3). Histopathology findings of infected birds showed leukocytic aggregation of in submucosa and infiltration among compound gland of the proventriculus (Fig. 1,A,C), mild interstitial and perivascular leukocytic infiltration of with vacuolar degeneration of the pancreas (Fig. 1, B), focal necrosis and hemorrhages of liver (Fig. 1, E), necrosis of the heart muscle fibers and replacement with reticular cells and atrophy the intestinal villi and partial to complete desquamation (Fig. 1, D).

Table 1: Experimental Design

\begin{tabular}{|c|c|c|c|c|c|c|c|c|}
\hline \multirow{2}{*}{ Grp } & \multirow[t]{2}{*}{ No of bird } & \multicolumn{3}{|c|}{ infection } & \multicolumn{2}{|c|}{ Performance parameter } & \multirow{2}{*}{\multicolumn{2}{|c|}{ Other parameters }} \\
\hline & & Dose & Route & Age & $\mathbf{B W}$ & BG & & \\
\hline A1 & 20 & $\Xi$ & Oral & \multirow{3}{*}{$\begin{array}{l}\text { 믕 } \\
\text { 号 } \\
\text { J } \\
\text { I }\end{array}$} & \multirow{3}{*}{$\begin{array}{l}\vec{n} \\
\stackrel{n}{n} \\
\stackrel{\infty}{N} \\
\vec{N}\end{array}$} & \multirow{3}{*}{$\begin{array}{l}\vec{D} \\
\stackrel{n}{\dot{y}} \\
\dot{J}\end{array}$} & \multirow{3}{*}{ 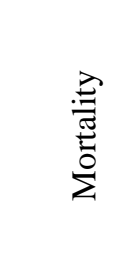 } & \multirow{3}{*}{ 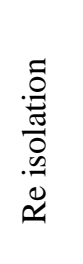 } \\
\hline A2 & 20 & 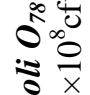 & Ocular & & & & & \\
\hline A3 & 20 & $\dot{x}$ & $\mathrm{I} / \mathrm{M}$ & & & & & \\
\hline B1 & 20 & $\stackrel{\infty}{\stackrel{\infty}{\circ}}$ & Oral & \multirow{3}{*}{$\begin{array}{l}\text { 믐 } \\
\text { त्ञ̄ }\end{array}$} & \multirow{3}{*}{ 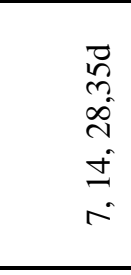 } & \multirow{3}{*}{$\begin{array}{l}\text { D } \\
\text { r } \\
0\end{array}$} & \multirow{3}{*}{ 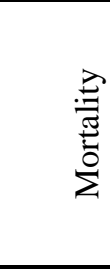 } & \multirow{3}{*}{ 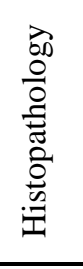 } \\
\hline B2 & 20 & $\begin{array}{l}\bar{\Xi} \\
\text { ก̣ }\end{array}$ & Ocular & & & & & \\
\hline B3 & 20 & 201 & $\mathrm{I} / \mathrm{M}$ & & & & & \\
\hline $\mathbf{C}$ & 20 & - & & - & & & & \\
\hline
\end{tabular}

Table 2: Results of viral and bacterial isolation and identification from sampled farms

\begin{tabular}{|c|c|c|c|c|c|c|c|}
\hline \multirow{2}{*}{ IA } & \multirow[b]{2}{*}{ Organ } & \multirow{2}{*}{ Ross (11) } & \multirow{2}{*}{ Hubbard (40) } & \multirow{2}{*}{ Sasso (19) } & \multicolumn{3}{|c|}{ E.coli Serotyping } \\
\hline & & & & & Isolates & No & $\%$ \\
\hline \multirow{6}{*}{ 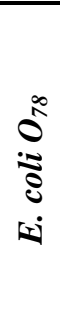 } & Liver & $1 / 11$ & $5 / 40$ & $2 / 19$ & \multirow{6}{*}{$\begin{array}{c}O_{55} \\
O_{87} \\
O_{119} \\
O_{125}\end{array}$} & 9 & 26.5 \\
\hline & Spleen & $0 / 11$ & $3 / 40$ & $2 / 19$ & & 13 & 38.2 \\
\hline & Lung & $2 / 11$ & $4 / 40$ & $2 / 19$ & & \multirow{4}{*}{$\begin{array}{l}4 \\
8\end{array}$} & \multirow{4}{*}{$\begin{array}{l}18.4 \\
11.8\end{array}$} \\
\hline & Joint & $0 / 11$ & $0 / 40$ & $0 / 19$ & & & \\
\hline & H. blood & $1 / 11$ & $7 / 40$ & $2 / 19$ & & & \\
\hline & Bile & $0 / 11$ & $3 / 40$ & $0 / 19$ & & & \\
\hline \multirow{5}{*}{ 잉 } & Proventriculus & $1 / 11$ & $4 / 40$ & $2 / 19$ & - & - & - \\
\hline & Pancreas & $2 / 11$ & $5 / 40$ & $3 / 19$ & - & - & - \\
\hline & S. intestine & $0 / 11$ & $3 / 40$ & $2 / 19$ & - & - & - \\
\hline & Thymus & $3 / 11$ & $5 / 40$ & $4 / 19$ & - & - & - \\
\hline & Heart & $1 / 11$ & $0 / 40$ & $0 / 19$ & - & - & - \\
\hline
\end{tabular}

$\boldsymbol{I A}=$ Infective agent 
Table 3: Mean body weight of chicken post infection with E. coli \& REO

\begin{tabular}{|c|c|c|c|c|c|c|c|c|}
\hline \multirow{2}{*}{ Gr* } & \multirow{2}{*}{ 7days PI } & \multirow{2}{*}{ 14days PI } & \multirow{2}{*}{ 21days PI } & \multirow{2}{*}{ 28days PI } & \multirow{2}{*}{ 35days PI } & \multirow{2}{*}{$\begin{array}{l}\text { Comulative } \\
\text { B gain* }\end{array}$} & \multicolumn{2}{|c|}{ Mortality } \\
\hline & & & & & & & No. & $\%$ \\
\hline A1 & - & $338.9 \pm 0.63^{a}$ & $660.5 \pm 0.85^{b}$ & $1094.6 \pm 0.99^{b}$ & $1221.3 \pm 0.60^{b}$ & $882.4 \pm 0.77^{c}$ & & \\
\hline A2 & - & $338.9 \pm 0.63^{a}$ & $654.4 \pm 1.51^{c}$ & $1094.6 \pm 0.99^{b}$ & $1195.7 \pm 11.52^{c}$ & $856.8 \pm 11.26^{d}$ & & \\
\hline A3 & - & $338.9 \pm 0.63^{a}$ & $652.3 \pm 1.74^{c}$ & $1090.3 \pm 1.55^{\mathrm{c}}$ & $1175.3 \pm 4.15^{d}$ & $836.5 \pm 3.87^{\mathrm{e}}$ & $3 / 20$ & 15 \\
\hline B1 & $90.1 \pm 0.57^{b}$ & $240.1 \pm 1.74^{b}$ & $319.7 \pm 4.89^{d}$ & $628.7 \pm 1.25^{d}$ & $1090.5 \pm 0.88^{e}$ & $1047.9 \pm 0.91^{b}$ & $1 / 20$ & 5 \\
\hline B2 & $90.1 \pm 0.57^{b}$ & $241.7 \pm 1.98^{b}$ & $325.4 \pm 1.18^{d}$ & $627.2 \pm 0.70^{d}$ & $1090.6 \pm 1.22^{\mathrm{e}}$ & $1050.3 \pm 1.33^{b}$ & $1 / 20$ & 5 \\
\hline B3 & $84.8 \pm 0.26^{b}$ & $230.7 \pm 0.71^{c}$ & $299.6 \pm 1.08^{\mathrm{e}}$ & $606.2 \pm 1.04^{\mathrm{e}}$ & $1091.9 \pm 0.92^{e}$ & $1051.3 \pm 1.01^{b}$ & $7 / 20$ & 35 \\
\hline C & $161.4 \pm 50.09^{a}$ & $338.9 \pm 0.63^{a}$ & $679.7 \pm 0.67^{\mathrm{a}}$ & $1121.3 \pm 0.60^{\mathrm{a}}$ & $1626.1 \pm 1.03^{a}$ & $1584.7 \pm 1.05^{\mathrm{a}}$ & & \\
\hline
\end{tabular}

*Group A infected at 14 days old with E. coli $O_{78}$, Group B infected at day old with $R E O$, Group C uninfected $\mathbf{P I}=$ Post infection
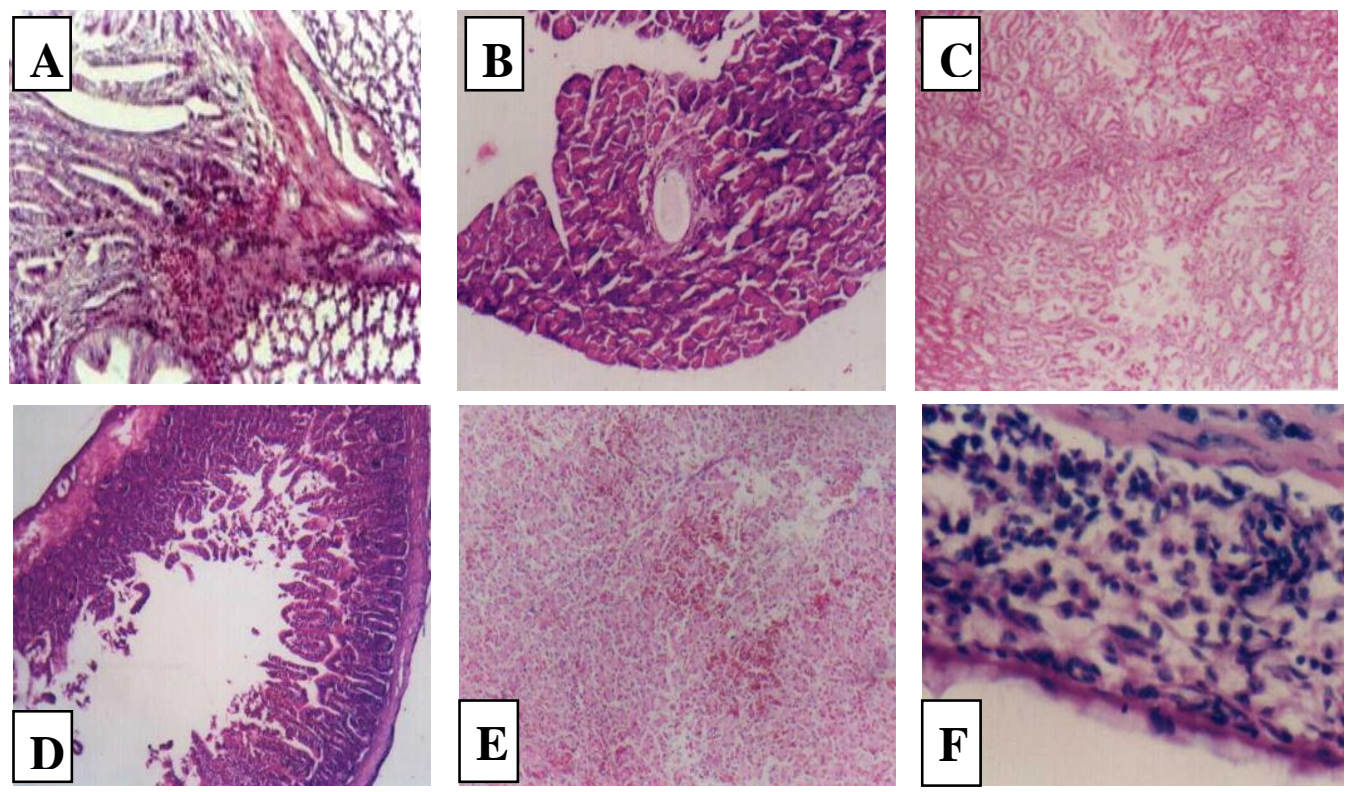

Fig. 1: Histopathological changes in REO infected chickens

A - Proventriculus: aggregation of leukocytes in submucosa H\&E x 150.

B - Pancreas: mild interstitial and perivascular leukocytic infiltration H\&E x 120.

C - Proventriculus: disseminated leukocytes infilteration among compound gland H\&E x 150 .

D - Small intestine: atrophied intestinal villi with partial desquamation H\&E x 120.

E - Liver: focal necrosis and hemorrhages H\&E x 120.

F - Heart: replacement of necrotic muscle fibers with proliferated reticular cells (intensive of heterophils) H\&E x 150.

\section{DISCUSSION}

E. coli $O_{78}$ infection in this study agreed Haritova et al. (2011) who noted that clinical signs of the infected chickens included depression, anorexia, increased water consumption, watery yellow-green diarrhea with dehydration and decreased mobility. Post-mortem findings show catarrhal enteritis, pericardis, perihepatitis and peritonitis in untreated and infected chickens. Reisolation percentage of E. coli $O_{78}$ from different tissue spleen, lungs and heart was $20 \%, 60 \%$ and $20 \%$ respectively, at 25 days post intra-tracheal infection. Un like Dheilly et al. (2011) who stated that mortality $13 / 60$ (21.7\%) with very severe air saculitis and peritonitis lesions and several perihepatitis lesions were observed and mean body gain over 3 weeks post air sac inoculation with 
E. coli $O_{78}$ was 232.2 gram. E. coli $O_{78}$ re-isolation from the internal organs was 21/59 of infected groups and the rate were $34 \%, 30.5 \%, 25.4 \%$ and $27.1 \%$ from air sac, pericardium, liver and spleen, respectively. Mahmoud and Edens (2005) recorded that enteropathogengic E. coli induced mortality $35 \%$ and significant reduction of the mean body weight 1.8 $\mathrm{kg}$ with bad feed conversion rate 2.1 comparing with uninfected group at 42 days old. Oliveira et al. (2010) that reported morbidity and mortality were $95 \%$ and $70 \%$ respectively, among chickens challenged with $0.2 \mathrm{ml}$ of a $3 \mathrm{~h}$ grown culture of $5.0 \times 10^{8} \mathrm{cfu} / \mathrm{ml}$ of E. coli $O_{78}$ via left air sac inoculation and postmortem findings was acute coli septicemia. While Peighambari et al. (2000) mentioned that intranasal infection of chickens with $E$. coli $O_{78}$ alone showed $18 \%$ pericarditis with total score lesions $6 \%$ with no deaths. The variance of mortality, body gain and recovery rates probably raised from differences of age, breed and immune status of susceptible birds, characterization of the pathogenic E. coli and route of experimental infection other than stress factors.

Regarding REO virus infection, unlike our results Saskia and Eva-Maria (2007) mentioned that high mortality (79\%) was seen within 7 days after IM inoculation while only one bird died at 10 days after oral inoculation but similarly to our findings of poor growth and helicopter chickens (mal-position of the feathers) were seen from day 4 and chickens stayed small until the end of the experiment in both groups. On the other hand Awandkar et al. (2012) reported that no mortality resulted from I/M infection with malabsorptin syndrome REO virus at 3days old but all birds were susceptible and developed the disease. The variation in mortality may be attributed to REO virus virulence of different serotypes and susceptibility of birds due to maternal antibodies. Our postmortem findings agreed with Saskia and EvaMaria (2007) where the liver was enlarged with multiple white to yellow foci, spleenomegaly with discoloration and hard consistency and hydropericardium and Nili et al. (2007) recoded that the intestines of the stunted chicks were pale and dilated with gaseous and watery contents. Enlarged proventriculus $(5.35 \%)$ and pancreas atrophy (3.5\%). The intestinal contents of the stunted chicks showed poorly digested food materials. Parallel to our results Songserm et al. (2002) recorded that the mean body weights of the oral infected groups were significantly lower than that of the control groups and there was no significant difference in weight gain depression between the REO inoculated groups of the two lines. At day 7 and 14 PI, a few broilers of each MAS inoculated group showed retarded feathering. Nili et al. (2007) recorded that there was a significant difference in live body weights between the treatment groups with and the controls on 8, 12, 14, 20, 30, and 35 days post inoculation. Their histological examinations revealed that enlarged proventriculi showed lymphocyte infiltration and dilatation of the glandular acini. Pancreatic histological changes were degeneration, vacuolation, loss of zymogen granules of acinar cells, and fibrosis. Moreover Songserm et al. (2002) noted that vacuolar degeneration was present in the intestinal villi day 2, 7 and 14 post infections with REO virus. At day 7 and 14 PI, lymphoid, macrophage and granulocytic infiltration into the lamina propria, cystic formation of crypts of Lieberkühn and villus atrophy were present in the small intestine. Saskia and Eva-Maria (2007) noted that multifocal or confluent necrosis with or without evidence of heterophils infiltration in the liver and spleen of infected groups. These findings agreed with ours.

It concluded that pathogenic $E$. coli $O_{78}$ and Reo virus are a serious threat for poultry industry. Both microbes are responsible for economic losses due mortalities and retardation of growth among meat type broilers. Prevention strategies should be adopted against especially in breeder flocks to produce maternal immunity capable to protect their progenies against $E$. coli and REO consequently enhancement of its performance.

\section{REFERENCES}

Awandkar P. Sudhakar; Sathish J. Manwar; Dilip M. Badukale and Mahesh B. Kulkarni (2012): Growth performance of broilers in experimental Reovirus infections. Vet. World. 5(11): 685-698.

Barnes, J.B. (1994): Pathogenesis of respiratory Escherichia coli and Pasteurella multocida infections in poultry. In: Proc. American Association of Avian Pathologists Symposium, Respiratory Diseases of Chickens and Turkeys, San Francisco, CA. pp 26- 35.

Dheilly Alexandra; Axelle Bouder; Laëtitia Le Devendec; Gwenaëlle Hellard and Isabelle Kempf (2011): Clinical and microbial efficacy of antimicrobial treatments of experimental avian colibacillosis. Veterinary Microbiology Volume 149, Issues 3-4, 5 May 2011, Pages 422-429.

Dho-Moulin, M. and Fairbrother, J.M. (1999): Avian pathogenic Escherichia coli (APEC). Vet. Res. 30(2-3): 299-316.

Ewers, C.; Janssen, T. and Wieler, L.H. (2003): Avian pathogenic Escherichia coli (APEC) Berl. Munch. Tierarztl. Wochenschr, 2003. 116(9-10): 381-395.

Ewing, W.H. (1984): Edwards and Ewing's Identification of Enterobacteriaceae. $4^{\text {th }}$ ed. Elsevier, Amsterdam, 536.

Hammerum, A.M. and Heuer, O.E. (2009): Human health hazards from antimicrobial-resistant Escherichia coli of animal origin. Clin. Infect. Dis., 48 (7): 916-921. 
Haritova Aneliya; Valentina Urumova; Mihni Lutckanov; Vladimir Petrov and Lubomir Lashev (2011): Pharmacokineticpharmacodynamic indices of enrofloxacin in Escherichia coli $\mathrm{O}_{78} / \mathrm{H}_{12}$ infected chickens. Food and Chemical Toxicology 49: 1530-1536.

Jakobsen, A. Kurbasic; Skjфt-Rasmussen, L.; Ejrnaes, K.; Porsbo, L.J.; Pedersen, K.; Jensen, L.B.; Emborg, H.D.; Agers $\phi$, Y.; Olsen, K.E.; Aarestrup, F.M.; Frimodt-Mфller, N. and Hammerum A.M. (2010): Escherichia coli isolates from broiler chicken meat, broiler chickens, pork, and pigs share phylogroups and antimicrobial resistance with communitydwelling humans and patients with urinary tract infection. Foodborne Pathog. Dis., 7(5): 537-547.

Jamalludeen, N.; She, Y.M.; Lingohr, E.J. and Griffiths, M. (2009): Isolation and characterization of virulent bacteriophages against Escherichia coliserogroups $\mathrm{O}_{1}, \mathrm{O}_{2}$, and $\mathrm{O}_{78}$. Poult. Sci. 88(8):1694-1702.

Mahmoud, K.Z. and Edens, F.W. (2005): Influence of organic selenium on hsp70 response of heatstressed and enteropathogenic Escherichia colichallenged broiler chickens (Gallus gallus). Comparative Biochemistry and Physiology, Part C 141: 69-75.

Mc Nulty, M.S. (1993): Reovirus; J.B. Mc Ferran, M.S. Mc Nulty (Eds.), Virus Infection of Birds, Elsevier Science Publishers, Amsterdam/London/New York/Tokyo. pp. 181-198.

Nili, H.; Jahantigh, M. and Nazifi, S. (2007): Clinical observation, pathology, and serum biochemical changes in infectious stunting syndrome of broiler chickens. Comp Clin Pathol. 16: 161-166.
Ogunbanwo S.T.; Sanni, A.I. and Onilude, A.A. (2004): Influence of bacteriocin in the control of Escherichia coli infection in broiler chickens in Nigeria. World Journal of Microbiology \& Biotechnology. 20: 51-56.

Oliveira Ana; Rui Sereno and Joana Azeredo (2010): In vivo efficiency evaluation of a phage cocktail in controlling severe colibacillosis in confined conditions and experimental poultry houses. Veterinary Microbiology. 146(3-4): 303-308.

Peighambari, S.M.; Julian, R.J. and Gyles, C.L. (2000): Experimental Escherichia coli respiratory infection in broilers. Avian Diseases. 44: 759-769.

Saif, Y.M. (2008): Oxford: Blackwell Publishing. Diseases of poultry.

Saskia van de Zande and Eva-Maria Kuhn (2007): Central nervous system signs in chickens caused by a new avian reovirus strain: A pathogenesis study. Veterinary Microbiology. 149(3-4): 422-429.

Songserm, T.H.; Engel, B.; Van Roozelaar, D.J; Kok, G.L.; Pijpers, A.; Pol, J.M.A. and Ter Huurne, A.A.H.M. (2002): Cellular immune response in the small intestine of two broiler chicken lines orally inoculated with malabsorption syndrome homogenates. Veterinary Immunology and Immunopathology. 85(1-2): 51-62.

Van de Zande, S. and Lin, F. (2005): 14th World Veterinary Poultry Congress, Istanbul, August, 2005, p. 325.

Van Loon, A.M.; Koopman, H.C.; Kosman, W.; Mumczur, J.; Szeleszczuk, O.; Karpinska, E.; Kosowaska, G. and Lutticken, D. (2001): Isolation of a new serotype ofavian reovirus associated with malabsorption syndrme in chickens. Vet. Q., 23: 129-133.

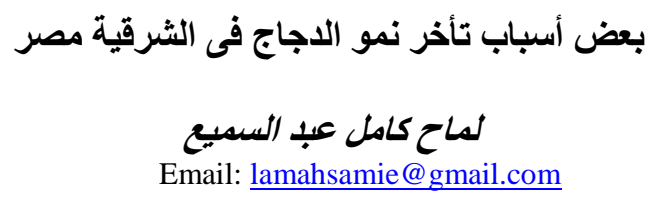

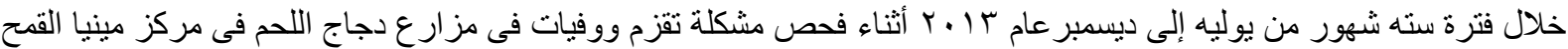

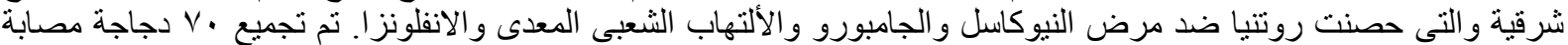

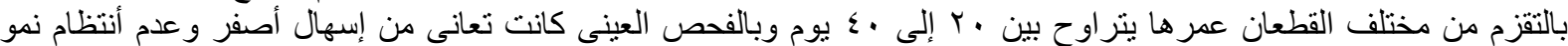

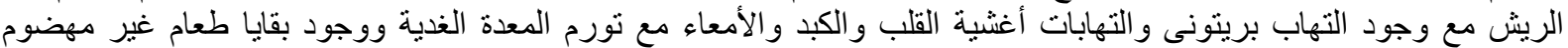

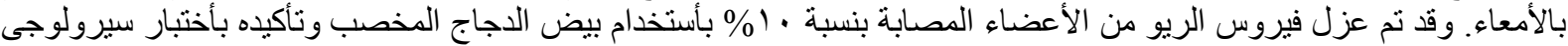

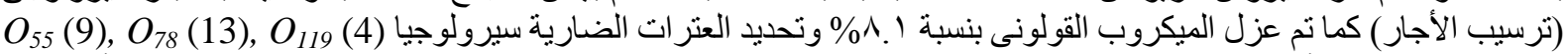
(8)

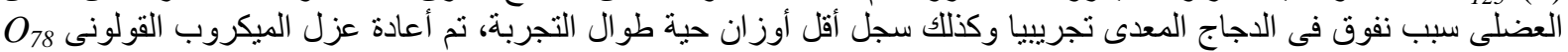

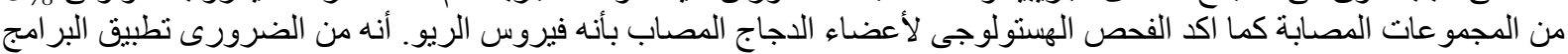

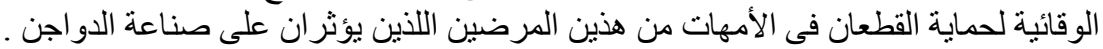

